\title{
Evaluation of the Agile Manifesto within Business Strategies
}

\author{
Andreas Kompalla ${ }^{1} \&$ Jan Kopia $^{1 *}$ \\ ${ }^{1}$ The Bucharest University of Economic Studies, Bucharest, Romania \\ *Jan Kopia, E-mail: j.kopia@gmx.net
}

\begin{abstract}
Every institution, company or single person needs a guideline aligning specific actions, processes and assets to an overall target. Recent research shows that guidelines of enterprises within the manufacturing branch or more specific within the automotive industry are almost identical. But new and emerging competitors force the traditional industry to adapt its business strategy and especially to increase flexibility. The internal and external changes within the manufacturing environment support this trend. The lead times are constantly shrinking and an increasing variety in customer demands has to be handled via new platforms and models. In conclusion, enterprises within the automotive industry need to increase agility and flexibility in order to stay competitive.

Within IT-project management, agility has been a focus since the end of the 1990s. Beneath that the automotive industry has applied several principles on the core value chain, logistics and production. But on the highest strategic level of an enterprise these principles have not been analyzed yet. This research paper is evaluating case studies in order to derive core agile aspects as well as principles. Based on that business strategies within the automotive branch are broken down and compared with these principles.

The result is that most of the agile aspects are not yet considered on the highest strategic business levels although they could increase the performance of enterprises within the automotive branch. But they need to be adapted to the specific characteristics.
\end{abstract}

Keywords

strategy, agile, lean methods, automotive industry, logistics, manifesto

\section{Introduction}

The core of this research paper is focusing on the evaluation and comparison of long-term planning and fixing of targets versus the agile as well as flexible adaption of enterprises according to their environment. Within the second chapter of this paper the characteristics of long-term-strategies, agile aspects and agile procedures are examined. Based on that business strategies within the automotive industry can be compared to further industries and especially the adaption of agile principles will be evaluated.

The first research method is benchmarking. The automotive industry could adapt best practices of more flexible and volatile industries such as social network and internet-based enterprises. The second 
approach is concentrating on existing research and scientific results on agile principles. Especially within IT projects and logistics processes there are defined agile procedures, which could be extended to the high-level business strategy in order to increase performance of automotive enterprises and to increase decision velocity.

\subsection{Definitions and Aspects of Business Strategies}

The term strategy does have various definitions and can be looked at via multiple perspectives. It has its routes within the military industry and can be separated into several aspects. A major characteristic of strategies is the goal setting as well as the formulation of visions (Schoemaker, 1992). But it does not end with the generation of mission and vision. A crucial part is the process and guideline, which is describing the path for transforming the vision into a value add, while applying the capabilities of a company (Amit \& Schoemaker, 1993). This procedure is summarized in the term of strategic management. Examples for strategic management frameworks are for example Porter's competitive "5 forces" (1980) and further "game theory" approaches (Shapiro, 1989). The CIA (Competitive innovation advantage) is based on the application of tangible and intangible resources. Porter's strategies, which have been focusing on decreasing costs and increasing differentiation, are strongly focusing on the resources of a company. Prahalad et al. (1990) concentrated on core competencies which are essential to remain competitive in the marketplace. Additionally, employee's skills and a wide knowledge database are crucial components. A similar but extended focus has been evaluated by Teece et al. (1997). They were focusing on dynamic capabilities, which are considering internal and external circumstances in order to react to a volatile environment. The conclusion was that the identification of core competences is as important as reacting to changing market circumstances. This concept of dynamic capabilities has been one of the most important frameworks for explaining core competences while the management and measurement is yet not sufficiently described (Cordes-Berszinn et al., 2013). An important aspect of strategies is differentiation. This can be either market or product focused.

After the Second World War, business strategies were concentrating mostly on fixed long term planning. Regardless of the branch, the market environment did not change frequently and especially not drastically in these times. Additionally to the slow change of the environment the information for these changes were not available instantly to all market participants. Today this is different. In general there is an easy and quick access to information and the globalized market is changing in shorter timeframes. The degree of changes is depending on the industry and branch but in general the amount companies acting in stable and fixed environments is shrinking. Therefore enterprises also needed to switch from product-driven strategies to customer focused strategies.

This switch is especially characteristic for the automotive branch. It has a history of more than 130 years coming from a very product-centric market. Initially production capacities have been aligned according to estimated long-term demands. Therefore the business strategies still contain long-term and planning characteristics of the branch itself. According to Kompalla and Kopia (n.d.), a majority of 
automotive strategies within the last 10 years are focusing on a few stakeholder-based goal, in specific growth, efficiency and sustainability. Additionally they switched their focus within the last 30 years to customer satisfaction and the fulfillment of customer demands (Kompalla et al., 2015). Automotive OEM's do have a high amount of similar quantitative and qualitative targets. Main KPIs are sales increase, operating margin and return on investment. The planning periods are mostly longterm and vary between 5 and 9 years. A specific characteristic is that these targets are rarely adjusted to actual developments during the planning period (Kompalla et al., 2015).

\subsection{Agile Principles}

One of the two research approaches (next to benchmarking) is focusing on the application of agile principles on business strategies itself. Hence, this chapter concentrates on agile principles within programming, because it was the root for additional applications of agile principles e.g., on project management (Cervone, 2011). As software development projects did change drastically in the last 30 years, at the end of the 1990s agile methods have been applied. In 2001 the agile manifesto was published first and is based on several methods which have been generated in the 1990s such as the scrum methodology (Maximini, 2015). A core element of agile concepts is to recognize that long-term planning and planning itself has limits and depending on the environment or customer demand it is more efficient not to waste time in describing a big solution in detail but to break it down to several prioritized tasks (Highsmith, 2001). Agile principles concentrate more on reacting to constant changes than to predicting them and to plan long-term solutions. The second aspect is the frequency of adaptions. Within agile concepts it is important to gather information about requirements constantly instead of a asking the customers once in a period of time. Thereby the customer interacts closely with the product and the project team which leads to further and more detailed requirements. The project team itself manages the tasks by itself and interacts with each other. The overall target and the core focus is a working product to which all activities should be steered (Ambler, 2001). The 12 agile principles of the agile manifesto are grouped into 4 areas of agility. These principles and guidelines will be compared with business strategies in chapter 3 .

\subsection{Lean and Agile Principles within Logistics and Production}

The shift to fulfilling customer demands instead of pushing products in to the market lead to changes within various areas of the automotive industry (Mintzberg, 1994; Howard et al., 2006). Especially within logistics and production management Just-in-time or Just-in-sequence principles became implemented, lean methods and the reduction of waste has been pushed as well as real-time communication of information across divisions and companies has been established. Megatrends such as globalization, the focus on diversified customer demands and sustainability (Howard et al., 2006) lead to the application of agile principles across the value creation stream. Especially the core value creation processes within production and production logistics needed to adapt to quickly changing customer demands. But the high-level business strategy was still classical instead of adapting to agility. Long-term predictions of demands lead to cycle and sales plans and periodic data analysis affected the 
qualitative and quantitative targets. In the end the top-management defined a strategy, which was communicated to lower levels. Figure 1 shows the comparison of this classic strategy to agile business strategies, which empower management teams to pursue strategic directions, looks for patterns instead of pure collections of data and constantly adapts to changing demands.

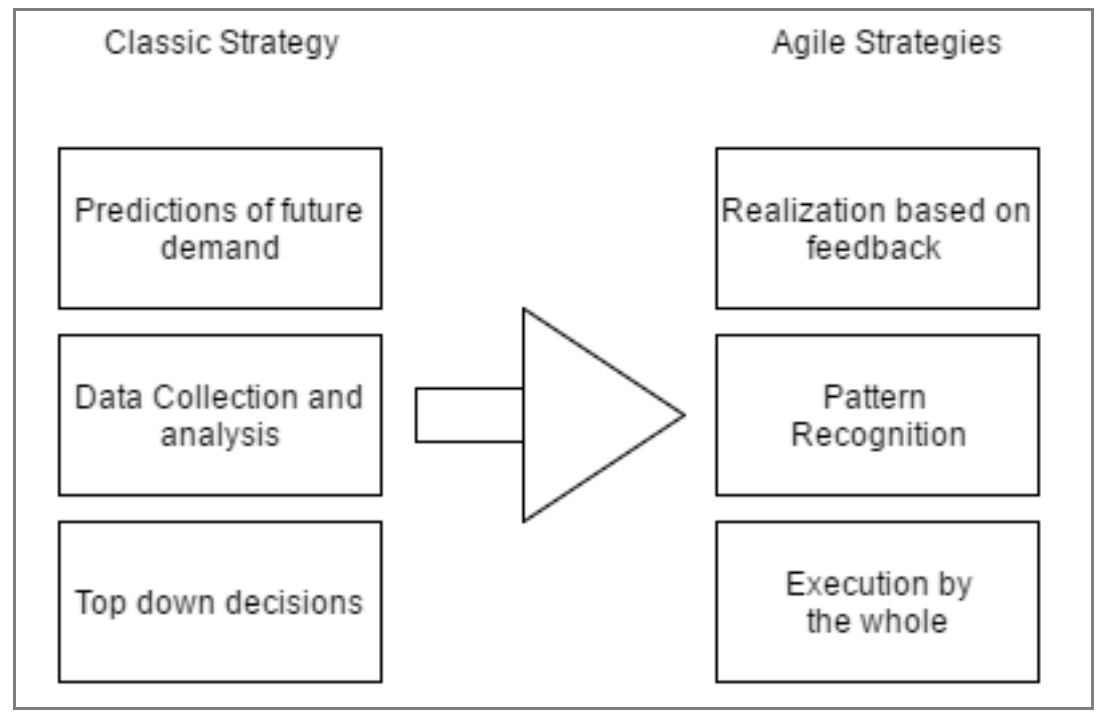

Figure 1. Classic Strategies vs. Adaptive Strategies

Source: Own representation c.f. monitor institute, 2012.

On a lower business level such as Supply Chain Management the classic aspects have changed. Many activities have been outsourced and only core activities, which provide a competitive advantage remained in-house. Today, the average value-add in-house shrunk to 30-35\% (Maurer, 2004) and all corresponding activities have been outsourced. Consequently all internal and external processes needed to be connected effectively and thoroughly. In order not to loose a single unit in the production schedule the whole supply chain needed to be streamlined and new principles emerged to identify waste as well as interconnect relevant processes (lean and pull principles).

These connections are defined by supply chain management, which has the target to design and manage value-added processes passing internal or external barriers to fulfill the customer demand (Fawcett et al., 2007).

Supply chains consist of several actors, which are the same across all industries: Suppliers, producers, distributors and customers (Hugo et al., 2008). Within the area of supply chain management "lean" aspects have been widely discussed. Starting with the introduction of the Toyota Production System Lean methodologies have been emphasized (Womack, Jones, \& Roos, 1990). The main idea "lean" thinking is to reduce and eliminate waste, which leads to an increase of efficiency and ideally to a decrease of production defects. Typical fields of application regarding lean principles are mass productions with fixed cycle times and standardized production lines. These lean principles are almost 
standard within the supply chain and the production lines of medium to big sized car manufacturers.

Key players such as retailers and customers increase their importance and influence. Due to a steady growth of competition and variants the customer and sales channel are focused on. Therefore manufacturers do have to consider all aspects of the value creation. Starting from in-time delivery up to to providing the highest quality within the right price range to the right customer (Zhang \& Cheng, 2006). Business strategies support these targets and especially the supply chain strategy, as one aspect of the business strategy itself, focuses on these topics. Additionally a set of competitors and suppliers complements the view on business strategies (Cohen \& Rousell, 2005; Hugo et al., 2004).

But due to constant and increasingly fast changes in globalization, external effects (e.g., laws) and technological advances strategies have to consider further aspects. As development cycles and product life cycles shrink there is a constant need for new innovations and inventions. Therefore it becomes more and more important not only to focus on the pure fulfilment of customer needs but also on the transformation into value (Teece, 2010).

In order to cope with increasing speed of changes and to react quick to external effects agile principles can be applied. Similar to the definition of business strategies there are multiple ways on describing the term agility. According to Pandey et al. (2009) agility can be seen as a business competence, which affects multiple layers of a business starting from organizational structures to information systems, logistics processes and also mindsets. In order to switch to an agile method the key is to overcome barriers in the mindset of people (Joseph, 1994; Kohzab, 2000)

Especially within manufacturing and logistics lean and agile are often mixed. While Lean approaches are focusing on the efficiency of processes agile methods try to capture quickly changing customer demands within the approach. Another contrast is the urge to standardize and unify procedures and products within lean methodologies while agile principles focus more on highly variable and diversified processes. Following figure summarizes several aspects, which are relevant for agile and lean principles.

Table 1. Comparison of Lean and Agile Aspects within Production and Logistics

\begin{tabular}{lcl}
\hline Lean logistics/manufacturing & & Agile logistics/manufacturing \\
\hline Focus on efficiency & vs. & Flexible to meet demands \\
Eliminate waste & vs. & Fulfill customer demands \\
Concentrate on customer service & vs. & Focus on costs \\
Solutions for long periods/Stability & vs. & Velocity depending on customers requirements \\
degree of utilization, productivity & vs. & Lead times and service levels \\
General, Standardization & vs. & Adaptive and variable \\
Formal long-term planning cycles & vs. & Self-structured by staff, less structured in advance
\end{tabular}

Source: Own representation based on Water, 2003. 
According to Victor et al. (1998) agility and "Lean" is interconnected. In specific, lean can be considered to come first and after lean processes have been established, agile aspects can be looked at. In scientific literature the term "leagile" has been established in order to emphasize that both approaches merged into each other (Vinodh et al., 2009) and create a strategy with hybrid characteristic. Based on the environment of a company the decoupling point can be set in a way that it can react flexible and efficient (Rachel, 1999). In this way the company can respond in a lean and efficient way up to the decoupling point (e.g., frozen zones within production) and afterwards focus on agile principles regarding customer demands (Christopher, 2005). Depending on the decoupling point various hybrid strategies emerged. The Pareto Rule (Christopher, 2005), base and surplus demand (Krishnamurthy et al., 2007) or the principle of postponement (Hilletofth, 2009) is just a selection of possible ways how to align lean and agile supply chains based on the point in which actual customer-requirements match with the forecast. The decoupling point affects many topics within the supply chain such as inventory management or the set-up of IT-systems and leads to a decision whether producing to forecasts (with the risk of stock increase) or to a defined order (Bowersox et al., 2010). Within the automotive industry lean approaches are embedded within the integrated supply chain. The application of lean and agile aspects, based on the example of a German automotive manufacturer, has been analyzed by Ambe et al. (2010). BMW applies all Lean methods, which have been categorized as relevant such as Total quality management, Just-in-Time manufacturing or Benchmarking. In contrast, just a selection of all analyzed features do show agile characteristics such as build-to-order, Flexibility and Adaptability.

\begin{tabular}{lcc}
\hline Features of BMW & Lean characteristics & Agile characteristics \\
\hline Just-in-time manufacturing & $\sqrt{ }$ & \\
Total quality management & $\sqrt{ }$ & \\
Reengineering & $\sqrt{ }$ & $\sqrt{ }$ \\
Build-to-order & $\sqrt{ }$ & \\
Benchmarking & $\sqrt{ }$ & $\sqrt{ }$ \\
Market sensitivity & $\sqrt{ }$ & $\sqrt{ }$ \\
Differentiation & $\sqrt{ }$ & \\
Flexibility & $\sqrt{ }$ & $\sqrt{ }$ \\
Competency & $\sqrt{ }$ & $\sqrt{ }$ \\
Adaptability & $\sqrt{ }$ & \\
Collaborative relationships & $\sqrt{ }$ & \\
Information systems and integration & $\sqrt{ }$ & \\
\hline
\end{tabular}

Figure 2. Analysis of Lean and Agile Characteristics of BMW

Source: Ambe et al., 2010.

One of the current challenges within the automotive industry is an increasing customer demand regarding variants and complete car characteristics as well as usage models. Furthermore, the amount of models and platforms is increasing whereas the product usage lifetime shrinks and external effects such as environmental regulations force OEMs to act and react in a flexible way.

Published by SCHOLINK INC. 


\section{Method}

In order to identify differences and similarities, this research compares agile methods, which were introduced in the first chapter as core strategies in the emerging global market with more plan-based methods used in traditional industries. The authors assume that companies are challenged by a highly competitive market place, which is Volatile, Uncertain, Complex and Ambiguous (VUCA), which increased over the years. The fours factors vary depending on the industry so certain methods and business strategies will have a more positive effect on the efficiency of organization than others.

The result of the comparison can be seen in Table 2 .

\section{Results}

The findings were analyzed based on different branches and industries, from very agile "new economy" companies acting in a highly reactive sector to traditional manufacturing companies.

\subsection{Agile Methods in Companies of the New Economy}

Companies of the new economy, which grew to large enterprise within the last ten to fifteen years, follow an innovative approach, which is highly adaptive but also self-tuning. Strategy is an on-going process and the possibility to execute a self-tuning and flexibly strategy to survive in the dynamic and complex environment (Reeves et al., 2015). The main aspects of this "agile" approach are three core processes: Rapid adaption (which means being agile), open to learning via trial and error (ability to adapt) and leveling exploring and exploiting (ambidexterity). Typical global players of that field (as Google, Facebook, etc.) act on these principles. They experiment a lot by the creation and testing of new solutions on their customers, adapt to customers' needs and react quickly regarding changes - they also shape the preferences of their customers by constantly offering various products and possibilities. A typical internet-based company operates a flexible IT-based environment which itself is organized in a very agile way. This means that functionalities are developed and integrated into the platform on a permanently basis. The customer is constantly challenged with new features. These features are often tested directly with customers in order to get an immediate response from the market. This way these organizations can quickly change functionalities of products or remove those completely if they are not meet the expectations. This trial and error phase is different to more traditional ways of identifying what the market wants (interviews, theoretical market analysis, focus groups, etc.). Investments are made after the feedback of the broad base of customers can be clearly predicted. These agile characteristics can usually also be seen on a strategic and visionary level as these companies are able to adapt to other markets or customers' needs very quickly. This way companies can also investigate more markets at the same time. The research result of Studeny (2015) shows that very successful companies implement more of the generic strategies of Porter (2013). A constant challenge of the strategy is usually done in regular cycles with an ongoing co-creation process starting from the identification of the market needs through customer feedback and ending with the initiation of the development processes. The last step can usually be done also from the lower management, which enhances the 
change to quicker than competitors since the involvement of the top management usually takes more time. This market focused approach is typical for those companies and requires a culture of openness and an embracement of constant change and organizational learning. These values are crucial for every employee as well since these values are highly dependent on the action of every employee in the value creation process (Martin, 2015).

\subsection{Contrasting Agile Strategies to Plan-Based Strategies}

Traditional businesses especially within the manufacturing industry use plan-based strategies. The fact that they develop goods, which are tangible and cannot just be changed and removed from one day to the other (as in internet-based companies) means that the production process is more complex and resource-intensive. It therefore has to be planned more precisely to prevent risks of various kinds. These companies are compared with slow moving cash cows (Martin, 2015). This is also true for the strategy and business models of those companies which are fixed for longer periods and adjusted only slightly over time. This also results in different processes, and different organizational cultures and different systems which only get fine-tuned (Reeves, 2015). The business models are kept over a long period of time and invocations are based on products/services. The automotive sector for instance has a development lifecycle for cars which ranges between three to six years; most car manufacturers do not change the business models very often in that period. Most organizations in that field put a strong focus on quantitative targets (e.g., the sales target or operating margin). The average planning horizon these quantitative numbers is similar to the duration of the business strategy (which usually has a length of 5 to 7 years). Within this range the target stays fix and can be seen in public papers such as the yearly report etc. If new products are planned, they will be integrated into the fixed plan based on customer requirements which are defined for the future ("what will the customer expect from a car which is new introduced in the market in 5 years?"). Since these strict planning cycles any change to the production plan of a car increased the cost dramatically the closer it is to the actual production (considering the phase of a Pre-series and a normal series). It increases the complexity for production and for logistics, for quality, and fore procurement (see Table 2). This is why most changes are not being implemented after a certain time was reached.

This is a direct contrast to agile principles (see previous chapter) which encourage change and a very close customer relationship including quick adoptions. Agile methods are designed for this close relationship and quick changes (Boehm \& Turner, 2004).

But it might be useful for traditional plan-based companies to adapt some of the agile principles. Sudden changes in the environment (e.g., the oil-prices and the resulting change in customers behavior) could mean a dramatic situation. Most larger companies assess that topic with their enterprise risk management and should create mitigations which also involve agile principles. Constant global uncertainty in gasoline prices, exhaust values, etc., are mandatory indicators for a car manufacturer to change their market position by producing products which are electric based, etc. But it could be too late considering a production life cycle of 5 years. Therefore it is important to start adopting agile 
principles such as experimentation, rapid prototyping, direct customer feedback, etc. This is not only true to prevent catastrophic situation but also for the normal business strategy of a car manufacturer. A constantly adjusted market position might by more useful to be prepared in today's market environment Most car manufacturer today already use some agile principles by executing methodologies as lean production, Total Quality Management (TQM), etc., which also put the focus on involvement and motivation of employees but the overall strategy is still very traditional. Volkswagen for instance uses a centralistic and top-down driven decision approach (Wall Street Journal, 2016).

Table 2. Comparison of Agile Principles, Agile Strategies and Traditional Plan-Based Strategies

\begin{tabular}{|c|c|c|c|}
\hline & $\begin{array}{l}\text { Agile aspects according } \\
\text { to agile manifesto }\end{array}$ & $\begin{array}{l}\text { Characteristic of business } \\
\text { strategy }\end{array}$ & $\begin{array}{l}\text { Agile principle applied } \\
\text { on business strategy? }\end{array}$ \\
\hline $\begin{array}{l}\text { Example of } \\
\text { Application }\end{array}$ & $\begin{array}{l}\text { Software development, } \\
\text { Agile production or agile } \\
\text { logistics }\end{array}$ & Automotive industry & $\begin{array}{l}\text { Comparison of agile } \\
\text { principles in software } \\
\text { development and } \\
\text { business strategies in } \\
\text { Automotive industry }\end{array}$ \\
\hline \multirow{3}{*}{$\begin{array}{l}\text { 1. Cluster: } \\
\text { Felxibility }\end{array}$} & $\begin{array}{l}\text { Flexibility regarding } \\
\text { varying circumstances } \\
\text { regardless of } \\
\text { development and } \\
\text { production stage }\end{array}$ & $\begin{array}{l}\text { Frozen zones and long } \\
\text { lasting business strategies } \\
\text { with targets, that do not get } \\
\text { changed often }\end{array}$ & No \\
\hline & $\begin{array}{l}\text { Close connection and } \\
\text { interaction between } \\
\text { people who decide and } \\
\text { people that execute }\end{array}$ & $\begin{array}{l}\text { Business strategy is defined } \\
\text { mostly centrally by highest } \\
\text { level of management }\end{array}$ & No \\
\hline & $\begin{array}{l}\text { Focus on the functional } \\
\text { product and incremental } \\
\text { value add weekly }\end{array}$ & $\begin{array}{l}\text { Defined stages with } \\
\text { Planning, Definition, } \\
\text { Communication and } \\
\text { Operation }\end{array}$ & No \\
\hline \multirow{2}{*}{$\begin{array}{l}\text { 2. Cluster: } \\
\text { Information }\end{array}$} & $\begin{array}{l}\text { Working as closely } \\
\text { together as possible } \\
\text { (locally) }\end{array}$ & Decentralized working places & No \\
\hline & $\begin{array}{l}\text { Constant but small } \\
\text { value-add steps }\end{array}$ & Periodic long-term changes & No \\
\hline
\end{tabular}




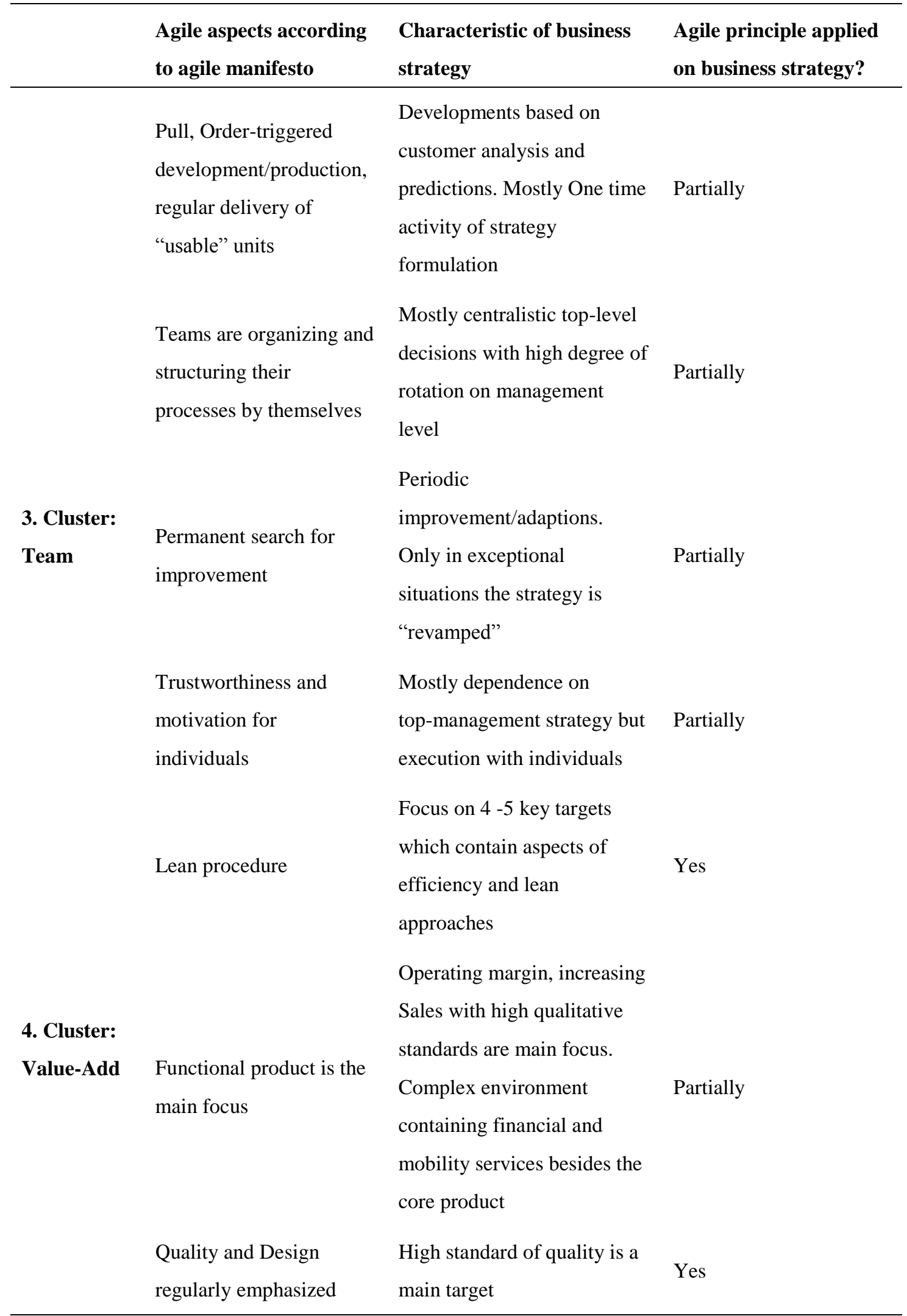

Source: Own representation based on chapter 1.2, 3.1 and 3.2. 


\section{Discussion}

Agile organizations and traditional plan-based organizations have different methodologies regarding their way of operating their businesses. This results in different strategies. The problem of today's market place is that it is challenged more than ever before the by the four dimensions of being volatile, uncertain, complex and ambiguous. This is also true for industries with different product development lifecycles such as car manufacturing. Agile principles are able to adapt quickly to the customers' needs. Therefore car manufacturer need to incorporate some agile principles as well since they face the same challenge of an increasing market competition. Car manufacturer started many years ago to adopt principles such as lean and TQM, but do not adapt the business strategy itself. The change of the business strategy of traditional enterprises is still very slow resulting in an increased risk for these companies when faced with a quicker competitor (e.g., at the moment big car manufacturer are challenged by IT-based companies in the market of electric and self-driving cars). Introducing agile principles on a strategic level can lead to more success also in industries with longer development and production lifecycles such as the automotive sector.

Future research needs to extend the analysis to further branches and companies, which already applied agile principles on high-level business strategies. Moreover, agile principles could be more efficient if they are tested on new business models within the automotive industry such as car sharing or autonomous driving services. Case studies or simulations could provide a detailed measure to what extend agility can contribute to increasing business performance with respect to the specific branch or industry.

\section{References}

Ambe, I. M., \& Badenhorst-Weiss, J. A. (2010, August 18). Strategic supply chain framework for the automotive Industry. African Journal of Business Management, 4(10), 2110-2120.

Ambler, S. W. (2011). Examining the agile Manifesto. Retrieved December 8, 2015, from http://www.ambysoft.com/essays/agileManifesto.html

Beck, K. et al. (2001). Principles behind the agile Manifesto. Agile Alliance. Retrieved January 1, 2016, from http://www.agilemanifesto.org/

Boehm, B., \& Turner, R. (2004). Balancing Agility and Discipline: A Guide for the Perplexed (pp. 55-57). Boston, MA: Addison-Wesley.

Bowersox, D. J., Closs, D. J., \& Cooper, M. B. (2010). Supply chain logistics management (3rd ed.). McGraw-Hill, Singapore.

Cervone, H. F. (2011). Understanding agile project management methods using Scrum. OCLC Systems \& Services: International digital library perspectives, 27(1), 18-22. http://dx.doi.org/10.1108/10650751111106528

Christopher, M. (2005). Logistics and supply chain management: Creating value-added networks. Harlow, England: Prentice Hall. 
Christopher, M., \& Towill, D. R. (2000). An Integrated Model for the Design of agile Supply Chains (pp. 143-148). Proc. LRN Conference, Cardiff.

Cohen, S., \& Rousell, J. (2005). Strategic Supply Chain Management: The Five Disciplines for Top Performance. New York: McGraw-Hill.

Cordes-Berszinn, P. (2013, November). Dynamic Capabilities: How Organisational Structures Affect Knowledge Processes. Palgrave Macmillan.

Fawcett, S. E., Ellram, L. M., \& Ogden, J. A. (2007). Supply Chain Management: From vision to implementation. Upper Saddle River, New Jessey: Prentice Hall.

Highsmith, J. (2001). History: The agile Manifest. Retrieved from http://www.agilemanifesto.org

Hilletofth, P. (2009). How to develop a differentiated supply chain strategy. Industrial management and data systems, 109(1), 16-33.

Howard, M., Miemczyk, J., \& Graves, A. (2006). Automotive supplier parks: An imperative for build-to-order? Journal of Purchasing and Supply Management, 12, 91-104.

Hugo, W. M. J., Badenhorst-Weiss, J. A., \& Van Biljon, E. H. B. (2004). Supply chain management: Logistics in perspective (3rd ed.). Pretoria: Van Schaik.

Ireland, R. D., Hitt, M. A., \& Sirmon, D. G. (2003). A model of strategic entrepreneurship: The construct and its dimensions. Journal of Management, 29(6), 963-989.

Joseph, C. A. (1994). Foundations for Successful Continuous Replenishment Programs. The International Journal of Logistics Management, 5(1), 1-8.

Kompalla, A., Kopia, J., \& Tigu, G. (2016). Limitations of Business Strategies and Management Systems within Automotive Industry. INTED 2016 conference proceedings.

Kotzab, H. (2000). Managing the Fast Moving Goods Supply Chain-Does Efficient Customer Response Matter (pp. 336-342)? Proceedings of the Logistics Research Network Conference, Cardiff University, Wales.

Krishnamurthy, R., \& Yauch, C. A. (2007). Leagile manufacturing: A proposed corporate infrastructure. International Journal Production Performance Management, 27(6), 588-604.

Maximini, D. (2015). The Scrum Culture: Introducing Agile Methods in Organizations. Management for Professionals.

Mintzberg, H. (1994). The Rise and Fall of Strategic Planning: Reconceiving Roles for Planning, Plans, Planners. New York: The Free Press.

Pandey, V. C., \& Garg, S. (2009). Analysis of interaction among the enablers of agility in supply chain. J. Advances Manage. Res., 16(1), 99-114.

Porter, E. (2013). Wettbewerbsstrategie: Methoden zur Analyse von Branchen und Konkurrenten. Frankfurt.

Porter, M. E. (1980). Competitive Strategy. New York: Free Press.

Porter, M. E. (1990). The Competitive Advantage of Nations. New York: Free Press.

Prahalad, C. K., \& Hamel, G. (1990). The Core Competence Of The Corporation. Harvard Business 
Review, May-June.

Reeves, M., Love, C., \& Tillmanns, P. (2012). Your strategy needs a strategy. Harvard Business Review, September.

Reeves, M., Ming, Z., \& Venjara, A. (2015). The Self-Tuning Enterprise (cover story). Harvard Business Review, 93, 76-83. Business Source Premier.

Schoemaker, P. (1992). How to link strategic vision to core capabilities. Sloan Management Review, 34, 1.

Shapiro, C. (1989). The theory of business strategy. RAND Journal of Economics, 20(1), 125-137.

Studeny, M. (2015). Comparative Analysis of Business Success in the Automotive Industry Using a Grounded Theory Approach.

Teece, D. J. (2010). Business Models, Business Strategy and Innovation. Long Range Planning, 43, 172-194.

Victor, B., \& Boynton, A. C. (1998). Invented Here: A Practical Guide to Transforming Work. Cambridge, Mass: Harvard Business School Press.

Vinodh, S., Sundararaj, G., \& Devadasan, S. R. (2009). Total agile design system model via literature exploration. Ind. Manage. Data Syst., 109(4), 570-588.

Wall Street Journal. (2016). Retrieved March 10, 2016, from http://www.pressreader.com/china/the-wall-street-journal-asia/20160224/282037621234300

Womack, J. P., \& Jones, D. T. (1996). Lean Thinking. Simon and Schuster, NY. 